A mixed methods study of the psychological impact of the COVID-19 pandemic

\author{
Alayna L. Park, Ph.D. ${ }^{1}$, Clarissa V. Velez, B.S. ${ }^{1}$, and Jiyoung Song, B.A. ${ }^{2}$ \\ ${ }^{1}$ Department of Psychology, Palo Alto University \\ ${ }^{2}$ Department of Psychology, University of California, Berkeley
}

Note: This manuscript is currently under peer review (submission date: September 19, 2021). Please do not cite without the authors' permission. 


\begin{abstract}
Author Note
We thank Bruce F. Chorpita, Ph.D. and Jeea Yang, M.A. for their contributions to this study, as well as the many individuals who participated in this study. The authors declare that they have no conflict of interest. Correspondence concerning this manuscript should be addressed to Alayna Park, Ph.D., Department of Psychology, Palo Alto University, 1791 Arastradero Road, Palo Alto, CA 94304. Email: apark1@ paloaltou.edu.
\end{abstract}




\begin{abstract}
This study examined the psychological impact of the COVID-19 pandemic. In May 2020, adults living in the United States $(N=345)$ completed an online survey on their functioning, psychological stress, health locus of control, and emotion regulation. Inductive thematic analysis was used to identify themes in qualitative responses about the functional impact of the COVID19 pandemic. Latent profile analysis and regression models were used to examine patterns in participants' stress and changes in functioning. Qualitative and quantitative results converged to show that many participants were negatively impacted by the COVID-19 pandemic, albeit onethird of participants reported improved functioning since the start of the pandemic. Health locus of control and avoidant emotion regulation predicted increased stress. Age, essential worker status, health locus of control, and active emotion regulation predicted changes in functioning. These findings extend existing knowledge about the psychological impact of the COVID-19 pandemic and highlight opportunities for promoting mental health and functioning in the wake of the pandemic.
\end{abstract}

Keywords: COVID-19, functional impairment, psychological stress, mixed methods, emotion regulation 


\section{A mixed methods study of the psychological impact of the COVID-19 pandemic}

COVID-19 (SARS-CoV-2) evolved into one of the worst pandemics in United States history. The first cases of COVID-19 surfaced in Wuhan, China in December 2019, and the novel coronavirus quickly spread and upended daily life across the globe. COVID-19 surfaced in the United States in January 2020; and the following month, the nation declared a public health emergency. In March 2020, California became the first state to issue a stay-at-home order, and another 41 states hastily followed suit (Moreland et al., 2020). By May 2020, the toll of the pandemic was becoming evident on not only public health but also mental health in the United States (Gruber et al., 2021). The current study contributes to growing knowledge about American adults' mental health and functioning in the early months of the COVID-19 pandemic.

For context, in May 2020, the United States had 1.34 million total COVID-19 cases and 82,000 total deaths. The CDC was actively encouraging physical distancing practices (i.e., staying at least 6 feet away from other people outside of one's household) to curtail the spread of the virus, and 42 states had implemented stay-at-home orders (Moreland et al., 2020). These sudden public health mandates caused more than 140,000 businesses to temporarily shut down (Sraders \& Lambert, 2020) and contributed to the highest unemployment rate in the United States since the Great Depression (Center on Budget and Policy Priorities, 2021). Additionally, more than 124,000 U.S. schools were forced to transition to distance learning, creating challenges for students, parents, and teachers (Education Week, 2020).

These drastic changes to daily life substantively impacted Americans' mental health and functioning. Park et al. (2020) surveyed 408 adults living in the United States in May 2020 and found that $37 \%$ endorsed clinically elevated symptoms of psychological stress. More than threefourths reported changes in their daily functioning - predominantly in their number of social 
interactions, physical activity, time spent working, time spent caregiving, and sleep. These alarming levels of psychological stress and functional impairment are consistent with other studies on the mental health consequences of the COVID-19 pandemic. For instance, Gallagher and colleagues (2020) found high rates of stress, anxiety, depression, and functional impairment among a sample of American adults from March to May 2020. Similarly, results for a Center for Disease Control (2021a) survey showed that an estimated one-third of Americans had symptoms of anxiety and depression in April to July 2020.

Recent studies have begun to identify protective and risk factors for mental health and functioning during the COVID-19 pandemic. For instance, young adults between 18-34 years old were found to be particularly vulnerable to stress, anxiety, and depression during the pandemic, likely due to social isolation and financial instability (Varma et al., 2020). People of color were disproportionately affected by pandemic-related discrimination, job insecurity, and health complications (Kantamneni, 2020; Substance Abuse and Mental Health Services Administration, 2020) - all of which increased their risk for emotion dysregulation and functional impairment. Essential workers (e.g., healthcare workers, teachers, first responders, grocery store workers) were also at risk for deteriorated mental health and functioning due to constant exposure to COVID-19 and unsustainable labor demand (Sritharan \& Sritharan, 2020). Several studies have reported high rates of stress among parents (Acterberg et al., 2021; Freisthler et al., 2021), although one study conducted in Denmark identified living with children as a protective factor (Andersen et al., 2020). Additionally, the uncertainty that festered during the pandemic contributed to widespread fear, worry, and helplessness (Sigurvinsdottir et al., 2020).

The current study explored the psychological impact of the COVID-19 pandemic on adults living in the United States in May 2020. This mixed-methods study expands upon findings 
from Park et al. (2020) by providing a qualitative glimpse into Americans' functioning during the pandemic and by delving into patterns of reported stress and functioning. Specifically, this study aimed to: (1) characterize how American adults were impacted by the COVID-19 pandemic; and (2) examine predictors of stress and functioning in the early months of the pandemic. Through better understanding how Americans experienced the COVID-19 pandemic, we hoped to elucidate common psychological consequences and to illuminate opportunities for promoting well-being in the wake of the pandemic.

\section{Method}

All study procedures were approved by the institutional review boards of the University of California, Los Angeles and Palo Alto University.

\section{Participants}

Adults (18 years or older) living in the United States were recruited to participate in this study in May 2020 through Amazon's Mechanical Turk (MTurk). Participants $\left(N=345^{1}\right)$ included males (59\%) and females (41\%) from 42 states. Participants were predominantly early adults (51\% 18-35 years old, 39\% 35-54 years old, 10\% 55 years or older); 64\% identified as non-Hispanic White, 15\% as Hispanic/Latinx, $10 \%$ as multiethnic/multiracial, $7 \%$ as Black, and $5 \%$ as another race or ethnicity. More than one-third of participants (37\%) identified as an essential worker; $59 \%$ reported living with at least one youth, aged $0-17$ years, during the pandemic.

\section{Measures}

Participants completed an online survey with questions about their demographics, functioning, symptoms of stress, health locus of control, and use of emotion regulation strategies.

\footnotetext{
${ }^{1}$ This study includes a subsample from Park et al. (2020) that had at least partial data across all measures.
} 
Upon completing the survey, participants were directed to a list of mental health resources, including the National Suicide Prevention Lifeline, Crisis Text Line, and National Alliance on Mental Illness Helpline.

\section{Functional Assessment}

This measure, which was designed for the purposes of this study, is a self-report questionnaire that assesses functioning during the COVID-19 pandemic. The measure prompts respondents to compare their current functioning with their functioning before the COVID-19 pandemic across 12 domains (e.g., sleep, eating, physical activity; see Figure 1 for the list of functioning domains) using a 5-point Likert scale ranging from -2 (much less/worse than usual) to 2 (much more/better than usual). The measure also included an open-ended question that asked, "How has your life been impacted by the COVID-19 pandemic?"

\section{PTSD Checklist for DSM-5 (PCL-5)}

The PCL-5 (Weathers et al., 2013) is a 20-item self-report questionnaire that assesses for symptoms characteristic of a trauma- or stressor-related disorder. The measure prompts respondents to indicate the extent to which they are bothered by intrusion symptoms, persistent avoidance, negative cognitions and mood, and hyperarousal using a 5-point Likert scale ranging from 0 (not at all) to 4 (extremely), with higher scores indicating greater symptom severity. The PCL-5 has demonstrated strong internal consistency and test-retest reliability, as well as convergent and discriminant validity (Blevins et al., 2015). For the purposes of this study, slight modifications were made to the instructions (i.e., specifying "keeping in mind your experiences during the COVID-19 pandemic...") and one item (i.e., changing "suddenly feeling or acting as if the stressful experience were actually happening again" to "suddenly feeling or acting as if you were in danger"). 


\section{Multidimensional Health Locus of Control (MHLC)}

Participants in this study completed the MHLC, Form A. This measure is an 18-item selfreport questionnaire that assesses respondents' beliefs that health is determined by their own selves (6-item Internality subscale), others such as physicians or family members (6-item Powerful Others subscale), or chance, fate, or luck (6-item Chance subscale). The measure prompts respondents to indicate the extent to which they agree with statements about sources of control of one's health using a 6-point Likert scale ranging from 1 (strongly disagree) to 6 (strongly agree). Subscale scores range from 6-36, with higher scores indicating that the source has greater control of one's health. The MHLC has evidenced internal consistency, test-retest reliability, construct validity, criterion validity, and discriminant validity (Wallston et al., 1978).

\section{Use of Emotion Regulation Strategies}

This measure, which was designed for the purposes of this study, is a self-report questionnaire that assesses use of 20 different emotion regulation strategies. The measure prompts respondents to indicate how frequently they used each emotion regulation strategy over the last two weeks on a 4-point Likert scale ranging from 0 (not at all) to 3 (nearly every day). Emotion regulation strategies were categorized as either active (i.e., strategies designed to change how one thinks about the stressor or the nature of the stressor itself) or avoidant (i.e., strategies designed to keep one from directly addressing the stressor) by two independent raters. Any discrepancies between raters were resolved through consensus. An active emotion regulation score was calculated by averaging the 14 corresponding items: adjusting to the new normal, engaging in physical activity, engaging in pleasurable activities, engaging in mastery activities, engaging in positive self-talk, following a routine, journaling, practicing mindfulness, praying, searching for information about COVID-19, seeking support from family and friends, 
seeking support from a professional, taking precautions to protect self and others from COVID19, and using relaxation techniques. An avoidant emotion regulation score was calculated by averaging the six corresponding items: eating for comfort, shopping for comfort, trying to avoid thinking about COVID-19, using alcohol, using tobacco products, using marijuana or other recreational drugs.

\section{Qualitative Data Analysis}

An inductive thematic analysis (cf. Braun \& Clarke, 2006) was used to identify themes in participants' responses about the functional impact of the COVID-19 pandemic. First, two doctoral students reviewed all responses to the open-ended question about functioning and generated a list of initial semantic content codes. These initial codes were then organized into candidate themes and subthemes. Candidate themes included functioning domain (e.g., parenting, mental health), valence (i.e., positive, neutral or not specified, mixed, negative), and extent of impact (i.e., none to little, moderate to severe). Next, the same two doctoral students independently coded the responses within candidate themes and subthemes. Coders and the Principal Investigator met biweekly to resolve discrepancies through consensus. Through these discussions, themes and subthemes were refined (e.g., the subtheme of occupational functioning was separated into subthemes of employment/ finances and work environment), resulting in increasingly parsimonious coding over time. See Table 1 for functioning domain subtheme names and definitions.

\section{Quantitative Data Analyses}

All variables of interest were missing some data: age (1\%), change in eating (1\%), change in quality of social interactions (1\%), ethnicity/race (2\%), essential worker status (2\%), change in concentration $(2 \%)$, change in mood $(2 \%)$, change in number of social interactions 
(2\%), change in physical activity (2\%), change in sleep (2\%), MHLC Internality score (2\%), MHLC Chance score (2\%), change in bathing (3\%), MHLC Powerful Others score (3\%), change in time spent working (6\%), change in quality of work (6\%), PCL-5 score (7\%), living with youth $(8 \%)$, change in time spent caregiving (17\%), and change in quality of caregiving (17\%).. Accordingly, we used the missForest package in R (Stekhoven \& Bühlmann, 2012) to impute missing data based on data of other variables. MissForest is a robust multiple imputation method that has shown to outperform other methods of imputation, especially for mixed-type data. The imputation model included all variables used in analyses.

To identify patterns in participants' reported changes in functioning, we conducted latent profile analysis (LPA), using the mclust package in R (Scrucca et al., 2016). LPA is commonly used subgroups within a large heterogenous group. We employed maximum likelihood estimation procedure with 95\% CIs obtained through 1,000 non-parametric bootstrap and examined the Bayesian Information Criterion, Integrated Complete-data Likelihood, and results from the bootstrap likelihood ratio test to determine the optimal number of classes.

We used regression models to examine predictors of stress and changes in functioning in the early months of the COVID-19 pandemic. We estimated three linear regression models predicting PCL-5 score and three ordinal logistic regression models predicting latent classes of participants' reported changes in functioning. The first linear and ordinal logistic regression models included demographic predictors: age (18-34 years old, 35-54 years old, 55 years or older); race/ethnicity (Non-Hispanic White, Hispanic/Latinx, Black, another race/ethnicity or multiracial/multiethnic); essential worker status (yes/no), and living with youth (yes/no). The second models added MHLC Internality, Powerful Others, and Chance subscale score predictors. The third models added active and avoidance emotion regulation score predictors. We estimated 
multiple models to understand the associations between various predictors and participants' reported stress and changes in functioning.

\section{Results}

\section{Functional Impact of the Pandemic}

Results from LPA indicated that there were three subgroups in participants' reported changes in functioning: Class 1 (34\% of participants, 95\% CI [2.78 - 11.58]) representing improved functioning, Class 2 (12\% of participants, 95\% CI [-1.74 - 1.26]) representing mostly no change in functioning, and Class 3 (53\% of participants, 95\% CI [-6.23 - -0.73]) representing worse functioning. These classes and their degrees of change in the various domains of functioning are shown in Figure 1.

These quantitative results converged with qualitative findings showing that many participants reported that the pandemic negatively impacted their lives (see Table 2). Qualitative results showed that participants endorsed impacts in an average of 2.02 subthemes $(S D=1.11)$ : employment and finances (36\%), physical distancing (30\%), work environment (25\%), mental health $(20 \%)$, social interactions $(18 \%)$, parenting $(12 \%)$, precautionary behaviors $(10 \%)$, physical health $(9 \%)$, and resources (5\%). See Table 1 for quotes from participants about each of these subthemes. Most participants endorsed that the pandemic had a negative impact on their lives $(61 \%) ; 33 \%$ endorsed that the impact was neutral or not specified (e.g., "I am now working from home"), $5 \%$ endorsed that the impact was mixed, and $3 \%$ endorsed that the impact was positive. The majority of participants (77\%) disclosed that the COVID-19 pandemic had a moderate to severe impact on their lives. 


\section{Predictors of Stress and Functioning}

Estimates from the linear regression model including demographic, health locus of control, and emotion regulation predictors showed that chance health locus of control and avoidant emotion regulation predicted symptoms of stress (see Table 3). Specifically, PCL-5 scores were predicted to be .81 points higher for each 1-point increase in MHLC Chance subscale score and 14.91 points higher for each 1-point increase in avoidance emotion regulation score.

Estimates from the ordinal logistic regression model including all predictors showed that age, essential worker status, powerful others health locus of control, and active emotion regulation predicted functioning latent class membership (see Table 4). Specifically, the odds of belonging to a worse functioning latent class were .63 lower for participants aged 55 years and older than for participants aged 18-34 years old. The odds of belonging to a worse functioning latent class also decreased by .44 for essential workers, by .06 for each 1-point increase in MHLC Powerful Others subscale score, and by .49 for each 1-point increase in active emotion regulation score.

\section{Discussion}

The present study explored the psychological impact of the COVID-19 pandemic on adults living in the United States in May 2020. We specifically sought to extend current knowledge about the psychological repercussions of the COVID-19 pandemic by characterizing the functional impact of the pandemic and identifying predictors of American adults' stress and changes in functioning.

Our qualitative and quantitative findings converged to show the predominantly negative impact of the COVID-19 pandemic on Americans' daily life. Many participants endorsed 
struggling with reduced social support, financial and occupational challenges, and mental health concerns as a result of the pandemic. Notably, one-third of participants reported improved functioning since the start of the pandemic. This sizable minority of participants appeared to have little to no change in their number of social interactions, whereas the vast majority of participants endorsed markedly fewer social interactions than before the pandemic. These results are consistent with other studies depicting the concerning mental health toll of the COVID-19 pandemic and attributing symptoms of stress, anxiety, and depression to social isolation (e.g., Centers of Disease Control and Prevention, 2021a; Gallagher et al., 2020; Varma et al., 2020). Such findings point to the possibility that individuals who preferred limited social interactions before the pandemic or who maintained similar levels of social interactions during the pandemic may have been somewhat protected from the adverse mental health consequences of the pandemic. These findings also indicate the potential value of identifying ways for individuals to meaningfully engage with one another, while practicing physical distancing to prevent the spread of COVID-19.

This study also identified predictors of stress and functioning during the early months of the COVID-19 pandemic. Specifically, individuals who held beliefs that health is determined by chance and practiced avoidant emotion regulation strategies (e.g., using alcohol or other recreational drugs, eating for comfort) reported higher levels of psychological stress. Young adults, essential workers, and individuals who held beliefs that health is determined by others and who practiced active emotion regulation strategies (e.g., behavioral activation, diaphragmatic breathing) reported similar or improved functioning. These results suggest that health locus of control and emotion regulation strategies play central roles in individuals' stress levels and functioning. These results also illuminate opportunities to improve well-being. For example, 
disseminating information that individuals can protect themselves and others against COVID-19 through getting vaccinated, wearing a mask, and frequently washing their hands - as well as dispelling potentially harmful myths (Centers for Disease Control and Prevention, 2021b) - may counteract beliefs that health is determined by chance and, consequently, may improve both physical and mental health. Promoting implementation of active emotion regulation strategies and de-implementation (i.e., removal of harmful or ineffective practices) of avoidant emotion regulation strategies through universal and indicated mental health promotion may be another fruitful direction for improving well-being in the wake of the pandemic.

When health locus of control and emotion regulation were excluded from analyses, demographic factors, such as age, ethnicity and race, essential worker status, and living with youth, were associated with heightened stress. These results are consistent with other studies (e.g., Freisthler et al., 2021; Kantamneni, 2020; Sritharan \& Sritharan, 2020; Varma et al., 2020) and highlight the disproportionate impact that the COVID-19 pandemic has had on certain groups. Such findings emphasize the need for national efforts, such as extending coverage of government benefits and distributing evidence-based information about the virus and vaccines, to facilitate psychological recovery. It is also worth noting the sociopolitical turmoil that was simultaneously occurring in the United States during the COVID-19 pandemic. Highly publicized racial violence in policing and a contentious presidential election exacerbated already high levels of distress (American Psychological Association, 2020), bolstering calls for systemic change to promote well-being and functioning for all Americans.

Although this study has several strengths including its mixed methods investigation of the psychological impact of the COVID-19 pandemic with a large sample of American adults, there are some limitations. First, this study used convenience sampling and includes an 
underrepresentation of females, people of color, and adults aged 55 years and older (cf. United States Census Bureau, 2019). Second, this was a cross-sectional study that investigated Americans' mental health and functioning in May 2020. Although the measure assessing functioning prompted participants to compare their current functioning with their functioning before the pandemic, this study was designed to examine stress, functioning, and emotion regulation at a single point in time. Accordingly, we are unable to draw conclusions about temporal ordering nor causation (e.g., whether use of emotion regulation affected stress and functioning, stress and functioning affected use of emotion regulation strategies, or a third variable affected stress, functioning, and use of emotion regulation strategies). Third, this study used unvalidated measures to assess functioning and use of emotion regulation strategies during the COVID-19 pandemic.

\section{Conclusion}

This study provides a snapshot of Americans' mental health and functioning in May 2020, approximately four months after COVID-19 first surfaced in the United States and two months after the first stay-at-home orders were enacted. Findings reveal a grim picture of the negative impact of the pandemic on Americans' well-being. Fortunately, several public health advances have been made since these data were collected, including the development and widespread distribution of vaccines, lifting of stay-at-home orders and other pandemic restrictions, and re-opening of schools and businesses (Centers for Disease Control and Prevention, 2021c). These developments are likely to have a positive impact on American life and the long-lasting economic, social, and health stressors that many encountered during the height of the outbreak cannot be ignored. The same attention that was granted to curtail the COVID-19 pandemic must be dedicated to prevent a subsequent mental health pandemic. With 
concerted efforts, the United States has the potential to promote well-being and functioning in the wake of the pandemic and cultivate a culture in which mental health is prioritized and valued. 


\section{References}

Achterberg, M., Dobbelaar, D., Boer, O. D., \& Crone, E. A. (2021). Perceived stress as mediator for longitudinal effects of the COVID-19 lockdown on wellbeing of parents and children. Scientific Reports, 11(1), 1-14. https://doi.org/10.1038/s41598-021-81720-8

American Psychological Association (2020). Stress in America 2020: Stress in the time of COVID-19. https://www.apa.org/news/press/releases/stress/2020/report-june

Andersen, L. H., Fallesen, P., \& Bruckner, T. A. (2021). Risk of stress/depression and functional impairment in Denmark immediately following a COVID-19 shutdown. BMC Public Health, 21(1), 1-11. https://doi.org/10.1186/s12889-021-11020-3

Blevins, C. A., Weathers, F. W., Davis, M. T., Witte, T. K., \& Domino, J. L. (2015). The posttraumatic stress disorder checklist for DSM-5 (PCL-5): Development and initial psychometric evaluation. Journal of Traumatic Stress, 28(6), 489-498. https://doi.org/10.1002/jts.22059.

Braun, V., \& Clarke, V. (2006). Using thematic analysis in psychology. Qualitative Research in Psychology, 3(2), 77-101. https://doi.org/10.1191/1478088706qp063oa

Centers for Disease Control and Prevention (2021a). Anxiety and depression. https://www.cdc.gov/nchs/covid19/pulse/mental-health.htm

Centers for Disease Control and Prevention (2021b). Myths and facts about COVID-19 vaccines. https://www.cdc.gov/coronavirus/2019-ncov/vaccines/facts.html

Centers for Disease Control and Prevention (2021c). Science brief: COVID-19 vaccines and vaccination. https://www.cdc.gov/coronavirus/2019-ncov/science/science-briefs/fullyvaccinated-people.html 
Center on Budget and Policy Priorities (2021). Tracking the COVID-19 recession's effects on food, housing, and employment hardships. https://www.cbpp.org/research/poverty-andinequality/tracking-the-covid-19-recessions-effects-on-food-housing-and

Education Week (2020). Map: Coronavirus and school closures in 2019-2020 [Infographic]. Edweek.org. https://www.edweek.org/leadership/map-coronavirus-and-school-closuresin-2019-2020/2020/03

Freisthler, B., Gruenewald, P. J., Tebben, E., McCarthy, K. S., \& Wolf, J. P. (2021). Understanding at-the-moment stress for parents during COVID-19 stay-at-home restrictions. Social Science \& Medicine, 279, 114025. https://doi.org/10.1016/j.socscimed.2021.114025

Gallagher, M. W., Zvolensky, M. J., Long, L. J., Rogers, A. H., \& Garey, L. (2020). The impact of COVID-19 experiences and associated stress on anxiety, depression, and functional impairment in American adults. Cognitive Therapy and Research, 44, 1043-1051. https://doi.org/10.1007/s10608-020-10143-y

Gruber, J., Prinstein, M. J., Clark, L. A., Rottenberg, J., Abramowitz, J. S., Albano, A. M., Aldao, A., Borelli, J. L., Chung, T., Davila, J., Forbes, E. E., Gee, D. G., Hall, G. C. N., Hallion, L. S., Hinshaw, S. P., Hofmann, S. G., Hollon, S. D., Joormann, J., Kazdin, A. E., ... \& Weinstock, L. M. (2021). Mental health and clinical psychological science in the time of COVID-19: Challenges, opportunities, and a call to action. American Psychologist, 76(3), 409-426. https://doi.org/10.1037/amp0000707

Kantamneni, N. (2020). The impact of the COVID-19 pandemic on marginalized populations in the United States: A research agenda. Journal of Vocational Behavior, 119, 103439. https://doi.org/10.1016/j.jvb.2020.103439 
Manning, K., Eades, N. D., Kauffman, B. Y., Long, L. J., Richardson, A. L., Garey, L., Zvolensky M. J., \& Gallagher, M. W. (2021). Anxiety sensitivity moderates the impact of COVID-19 perceived stress on anxiety and functional impairment. Cognitive Therapy and Research, 45, 689-696. https://doi.org/10.1007/s10608-021-10207-7

Moreland, A., Herlihy, C., Tynan, M. A., Sunshine, G., McCord, R. F., Hilton, C., Poovey, J., Werner, A. K., Jones, C. D., Fulmer, E. B., Gundlapalli, A. V., Strosnider, H., Potvien, A., Garcia, M. C., Honeycutt, A., Baldwin, G., CDC Public Health Law Program, CDC COVID-19 Response Team, \& Mitigation Policy Analysis Unit (2020). Timing of state and territorial COVID-19 stay-at-home orders and changes in population movementUnited States, March 1- May 31, 2020. Morbidity and Mortality Weekly Report, 69(35), 1198. https://doi.org/10.1016/j.pnpbp.2020.110236

Park, A. L., Velez, C. V., Kannan, K., \& Chorpita, B. F. (2020). Stress, functioning, and coping during the COVID-19 pandemic: Results from an online convenience sample. The Behavior Therapist, 42(6), 210-216.

Scrucca, L., Fop, M., Murphy, T. B., \& Raftery, A. E. (2016). mclust 5: clustering, classification and density estimation using Gaussian finite mixture models. The R journal, 8(1), 289317.

Sigurvinsdottir, R., Thorisdottir, I. E., \& Gylfason, H. F. (2020). The impact of COVID-19 on mental health: The role of locus on control and internet use. International Journal of Environmental Research and Public Health, 17, 6985. https://doi.org/10.3390/ijerph17196985 
Sraders, A., \& Lambert, L. (2020, September 28). Nearly 100,000 establishments that temporarily shut down due to the pandemic are now out of business. Fortune. https://fortune.com/2020/09/28/covid-buisnesses-shut-down-closed/

Sritharan, J., \& Sritharan, A. (2020). Emerging mental health issues from the novel coronavirus (COVID-19) pandemic. Journal of Health and Medical Sciences, 3(2), 157-162. https://dx.doi.org/10.4103\%2Fpsychiatry.IndianJPsychiatry_372_20

Stekhoven, D. J., \& Bühlmann, P. (2012). MissForest-non-parametric missing value imputation for mixed-type data. Bioinformatics, 28(1), 112-118. https://doi.org/10.1093/bioinformatics/btr597

Substance Abuse and Mental Health Services Administration (2020). Double jeopardy: COVID19 and behavioral health disparities for Black and Latino communities in the U.S. https://www.samhsa.gov/sites/default/files/covid19-behavioral-health-disparities-black$\underline{\text { latino-communities.pdf }}$

United States Census Bureau (2019). Quick facts: United States. https://www.census.gov/quickfacts/fact/table/US/PST045219

Varma, P., Junge, M., Meaklim, H., \& Jackson, M. L. (2020). Younger people are more vulnerable to stress, anxiety, and depression during COVID-19 pandemic: A global cross-sectional survey. Progress in Neuropsychopharmacology \& Biological Psychiatry, 109, 110236. https://doi.org/10.1016/j.pnpbp.2020.110236

Wallston, K. A., Strudler Wallston, B., \& DeVellis, R. (1978). Development of the multidimensional health locus of control (MHLC) scales. Health Education Monographs, 6(1), 160-170. https://doi.org/10.1016/j.pnpbp.2020.110236 
Weathers, F.W., Litz, B.T., Keane, T.M., Palmieri, P.A., Marx, B.P., \& Schnurr, P.P. (2013). The PTSD Checklist for DSM-5 (PCL-5). Scale available from the National Center for PTSD at www.ptsd.va.gov. 
Figure 1

Latent classes of participants' reported changes in functioning

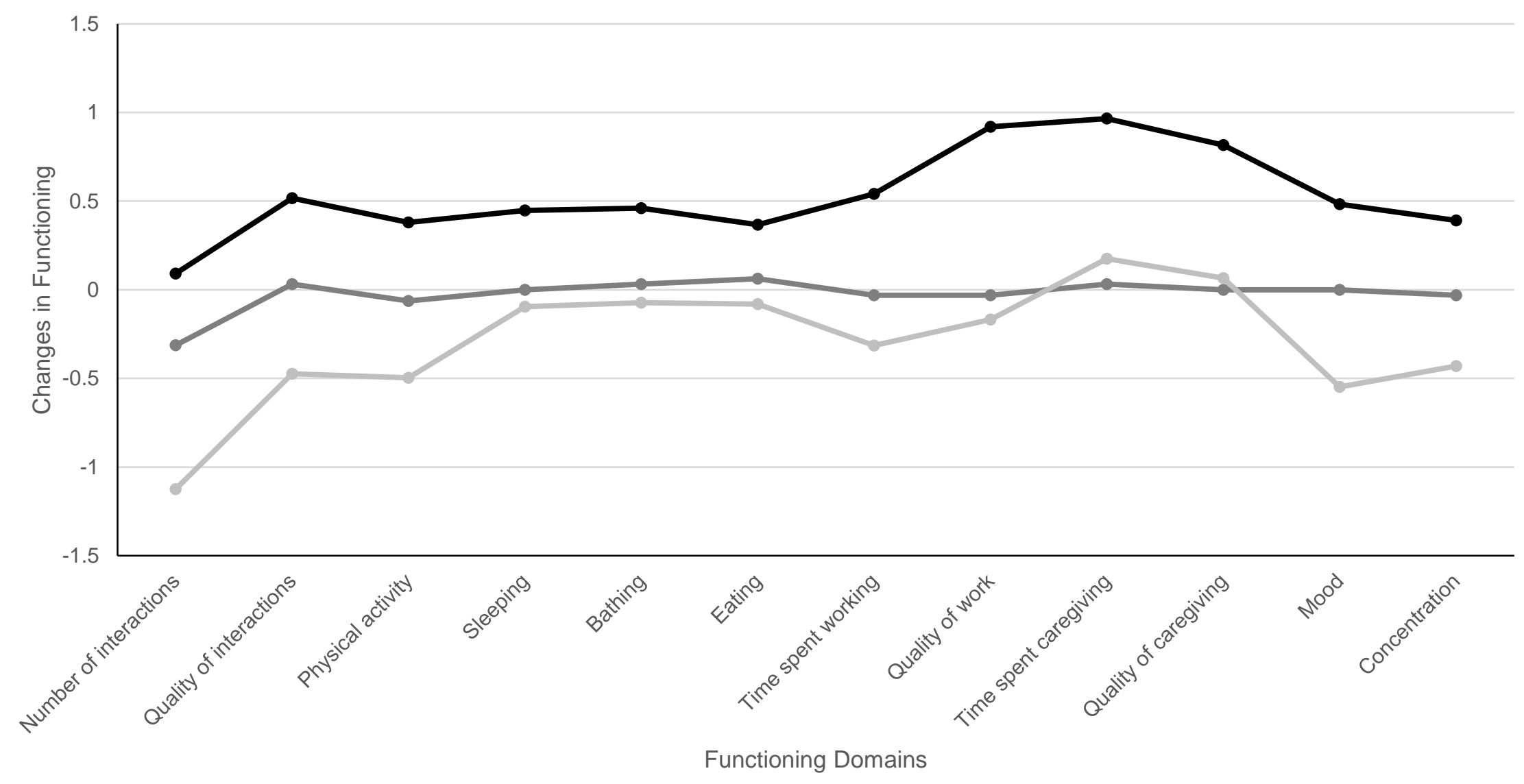

$\longrightarrow$ Class $1 \longrightarrow$ Class $2 \longrightarrow$ Class 3 
Table 1

Subthemes of functional impacts the COVID-19 pandemic

\begin{tabular}{|c|c|c|c|}
\hline Subtheme & Class 1 Exemplar Quote & Class 2 Exemplar Quote & Class 3 Exemplar Quote \\
\hline $\begin{array}{l}\text { Social interactions } \\
\text { Impact on social interactions, } \\
\text { such as spending more time with } \\
\text { family or feeling disconnected } \\
\text { from others }\end{array}$ & $\begin{array}{l}\text { "Spending more time with my } \\
\text { family because now I work from } \\
\text { home." }\end{array}$ & $\begin{array}{l}\text { "...It has mostly made me see } \\
\text { more of my children as they are at } \\
\text { home from college. I also don't } \\
\text { get to see my friends as I used to, } \\
\text { but we do [see each other] } \\
\text { online." }\end{array}$ & $\begin{array}{l}\text { "I'm no longer able to partake in } \\
\text { physical exercise at the gym, visit } \\
\text { my friends, and attend church } \\
\text { activities. COVID-19 has halted } \\
\text { all of my social activities..." }\end{array}$ \\
\hline $\begin{array}{l}\text { Physical health } \\
\text { Impact on physical health, such } \\
\text { as noticing changes in sleep or } \\
\text { appetite or having complications } \\
\text { after contracting the virus }\end{array}$ & “...healthy, good sleep." & N/A & $\begin{array}{l}\text { "I am sick still and my chest is } \\
\text { full of phlegm. People treat me } \\
\text { different, afraid they will get the } \\
\text { virus..." }\end{array}$ \\
\hline $\begin{array}{l}\text { Employment and finances } \\
\text { Impact on occupational } \\
\text { functioning or finances, such as } \\
\text { losing a job, having hours } \\
\text { reduced, or receiving } \\
\text { unemployment benefits }\end{array}$ & $\begin{array}{l}\text { "My wife and I are working from } \\
\text { home as much as possible... We } \\
\text { still have our jobs and healthy so } \\
\text { that is all we can hope for right } \\
\text { now." }\end{array}$ & $\begin{array}{l}\text { "Spouse has been laid off for } \\
\text { weeks and still hasn't received } \\
\text { unemployment. I'm working from } \\
\text { home and making slightly less..." }\end{array}$ & $\begin{array}{l}\text { "I am a teacher and went to a } \\
\text { building every day and was } \\
\text { surrounded by many adults and } \\
\text { students. Presently I am working } \\
\text { from home since [March 16, } \\
2020 \text { ] and only see my husband } \\
\text { daily - huge change! My son lost } \\
\text { his job, and his girlfriend has } \\
\text { been furloughed, so a lot of stress } \\
\text { there...My husband's salary is cut } \\
\text { in half because he is in sales and } \\
\text { companies aren't particularly } \\
\text { buying right now." }\end{array}$ \\
\hline
\end{tabular}




\section{Work environment}

Impact on work environment, such as working from home

\section{Parenting}

Impact on childcare or parenting responsibilities, such as needing to homeschool children or having children at home all day

\section{Mental health}

Impact on mental health, such as feeling fearful, anxious, down, or stressed
"I am working from home, and my wife needs to work still, so I am doing full work days, being a teacher to my kids, fixing food, and so on. If I lose time to work, I will continue into the evening. I work a lot anyway, so this is a great chance for me to continue to be responsible but not have the pressure of office space."

"The biggest impact has been having my kids at home all the time, and me working from home. Both of these things have been very positive, and my family wants to keep going this way in the future as well."

“...It has given me less [stress] and ability to have more rest since distancing and sometimes that the stay at home order has been put in place."
"I had to learn to work from home and organize a new work schedule and complete the rest of the activities at home."

"It's been hard to work at home and keep my kids occupied."

\section{makes me a little lonely."}

"All are working from home, which is challenging as not everyone is trained to do so. [I] have had to train and/or take on additional duties..."

"I am now working remotely and trying to help my child get through her schooling online. It has been very stressful trying to balance both of these well."

"I lost the interest of exercising and doing other productive things. I just feel like eating and sleeping the whole time. I have big mood changes and I get stressed easily." 


\section{Physical distancing}

Impact on functioning related to public health guidelines around physical distancing, needing to adhere to safer at home orders or in-person services for nonessential businesses being suspended

\section{Precautionary behaviors}

Impact on functioning related to precautions taken to prevent the spread of COVID-19, such as wearing a face mask, washing hands, or disinfecting surfaces

\section{Resources}

Impact on functioning related to the availability of resources, such as having difficulties obtaining food or other basic necessities
"Very safe in [home]."

"Slightly [impacted] purchasing of materials and groceries."
"I work from home and have been inside for 48 days now."

“...I wear a mask and gloves to avoid getting infected. Because I am 70, people have not had any problem with my precautions. I also cover up when I go shopping."

"It's hard to get groceries and other necessary supplies because... every store seems to be out of everything."
"It has been pretty tough especially since the stay at home orders started being put into place. I am not currently working as a result of the coronavirus. I also haven't been able to go to the gym or have any social gatherings with family or friends. Not having enough money is always a stressful thing but not being able to go out and be social to get your mind off things makes it worse."

"I have been afraid to venture out of my house. My immune system is immunocompromised, and I am very scared that any cough, sneeze, or sniffle may be directly related to COVID-19. I order all groceries and medicines online, and I wipe everything down when they arrive at my house."

"...it is hard to buy groceries in the supermarket."

\footnotetext{
Note: N/A = No participants in this functioning class reported impacts in this life domain.
} 
Table 2

Convergence of quantitative and qualitative functioning data

\begin{tabular}{|c|c|c|}
\hline Functional Impact & Quantitative & Qualitative \\
\hline Social interactions & $\begin{array}{l}\text { Participants reported fewer social interactions } \\
(M=-.66, S D=1.12) \text {, with slightly worse quality of } \\
\text { social interactions }(M=-.08, S D=.88) \text {, as a result of } \\
\text { the pandemic. }\end{array}$ & $\begin{array}{l}\text { Many participants reported that the pandemic } \\
\text { negatively impacted their level of social support. }\end{array}$ \\
\hline Physical health & $\begin{array}{l}\text { Participants reported slightly less physical activity } \\
(M=-.11, S D=1.00) \text {, slightly more sleep }(M=.07 \text {, } \\
S D=.88) \text {, slightly more bathing }(M=.11, S D=.85) \text {, } \\
\text { and slightly more eating }(M=.09, S D=.83) \text {, as a } \\
\text { result of the pandemic. }\end{array}$ & $\begin{array}{l}\text { Many participants reported that the pandemic did not } \\
\text { necessarily impact their physical health but caused } \\
\text { concerns about their own health and/or the health of } \\
\text { family and friends. }\end{array}$ \\
\hline Occupational & $\begin{array}{l}\text { Participants reported slightly less time working } \\
(M=-.03, S D=1.05, \text { with improved quality of work } \\
(M=.20, S D=.86) \text {, as a result of the pandemic. }\end{array}$ & $\begin{array}{l}\text { Many participants reported that the pandemic } \\
\text { negatively impacted their employment and/or } \\
\text { finances. }\end{array}$ \\
\hline Caregiving & $\begin{array}{l}\text { Participants reported more time spent caregiving } \\
(M=.43, S D=.87) \text {, with improved quality of } \\
\text { caregiving }(M=.29, S D=.78) \text {, as a result of the } \\
\text { pandemic. }\end{array}$ & $\begin{array}{l}\text { Participants reported a mixture of positive and } \\
\text { negative impacts of the pandemic on their parenting. }\end{array}$ \\
\hline Mental health & $\begin{array}{l}\text { Participants reported slightly worse mood }(M=-.15 \text {, } \\
S D=.83) \text { and concentration }(M=-.10, S D=.78) \text {, as } \\
\text { a result of the pandemic. }\end{array}$ & $\begin{array}{l}\text { Many participants reported that the pandemic } \\
\text { negatively impacted their mental health. This change } \\
\text { in mental health was largely attributed to physical } \\
\text { distancing. }\end{array}$ \\
\hline
\end{tabular}


Table 3

Standardized regression coefficients of demographic, health locus of control, and emotion regulation predictors on stress

\begin{tabular}{|c|c|c|c|c|c|c|c|c|c|}
\hline \multirow[t]{2}{*}{ Predictor } & \multicolumn{3}{|c|}{ Model 1} & \multicolumn{3}{|c|}{ Model 2} & \multicolumn{3}{|c|}{ Model 3} \\
\hline & $B$ & $S E$ & $t$ & $B$ & $S E$ & $t$ & $B$ & $S E$ & $t$ \\
\hline \multicolumn{10}{|l|}{ Age } \\
\hline $35-54$ years old & -7.69 & 2.10 & $-3.67 * * *$ & -3.75 & 1.82 & $-2.06^{*}$ & -2.54 & 1.53 & -1.67 \\
\hline 55 years or older & -9.53 & 3.31 & $-2.88 * *$ & -5.72 & 2.87 & $-1.99 *$ & -2.06 & 2.42 & -.85 \\
\hline \multicolumn{10}{|l|}{ Ethnicity/race } \\
\hline Black & -4.98 & 4.03 & -1.23 & -1.05 & 3.46 & -.30 & .21 & 2.91 & .07 \\
\hline Hispanic/Latinx & 6.63 & 2.46 & $2.70 * *$ & 3.41 & 2.12 & 1.61 & 2.88 & 1.78 & 1.62 \\
\hline Other & -2.58 & 3.24 & -.80 & 1.58 & 2.79 & .57 & 3.33 & 2.33 & 1.42 \\
\hline Gender (Female) & -2.74 & 1.97 & -1.39 & -.58 & 1.69 & -.34 & .88 & 1.42 & .62 \\
\hline Essential Worker & 9.86 & 2.09 & $4.73 * * *$ & 5.06 & 1.83 & $2.76^{* *}$ & 2.62 & 1.55 & 1.69 \\
\hline Living with Youth & 7.86 & 2.13 & $3.69 * * *$ & 4.20 & 1.85 & $2.27 *$ & 2.26 & 1.56 & 1.44 \\
\hline \multicolumn{10}{|l|}{ MHLC } \\
\hline Internality & & & & -.45 & .21 & $-2.12^{*}$ & -.37 & .19 & -1.95 \\
\hline Powerful Others & & & & .65 & .18 & $3.66 * * *$ & .17 & .15 & 1.10 \\
\hline Chance & & & & 1.37 & .18 & $7.71 * * *$ & .81 & .16 & $5.17^{* * *}$ \\
\hline \multicolumn{10}{|l|}{ Emotion Regulation } \\
\hline Active & & & & & & & 1.10 & 1.62 & .68 \\
\hline Avoidant & & & & & & & 14.91 & 1.32 & $11.31 * * *$ \\
\hline
\end{tabular}

Note: MHLC $=$ Multidimensional Health Locus of Control. ${ }^{*} p<.05, * * p<.01, * * * p<.001$. 
Table 4

Standardized regression coefficients of demographic, health locus of control, and emotion regulation predictors on worse functioning latent class membership

\begin{tabular}{|c|c|c|c|c|c|c|c|c|c|}
\hline \multirow[t]{2}{*}{ Predictor } & \multicolumn{3}{|c|}{ Model 1} & \multicolumn{3}{|c|}{ Model 2} & \multicolumn{3}{|c|}{ Model 3} \\
\hline & $B$ & $S E$ & Wald & $B$ & $S E$ & Wald & $B$ & $S E$ & Wald \\
\hline \multicolumn{10}{|l|}{ Age } \\
\hline $35-54$ years old & .05 & .28 & .03 & -.25 & .31 & .66 & -.25 & .31 & .66 \\
\hline 55 years or older & -.49 & .41 & 1.42 & -.85 & .44 & 3.81 & -1.01 & .46 & $4.86 *$ \\
\hline \multicolumn{10}{|l|}{ Ethnicity/race } \\
\hline Black & -.74 & .46 & 2.55 & -.87 & .49 & 3.23 & -.92 & .51 & 3.27 \\
\hline Hispanic/Latinx & -.56 & .31 & 3.35 & -.23 & .33 & .49 & -.32 & .33 & .93 \\
\hline Other & .65 & .54 & 1.45 & .31 & .59 & .27 & .07 & .59 & .02 \\
\hline Gender (Female) & .34 & .27 & 1.64 & .18 & .28 & .41 & .18 & .28 & .39 \\
\hline Essential Worker & -.84 & .27 & $9.51 * *$ & -.63 & .29 & $4.86^{*}$ & -.59 & .29 & $3.94 *$ \\
\hline Living with Youth & -.70 & .30 & $5.30 *$ & -.41 & .32 & 1.65 & -.38 & .32 & 1.35 \\
\hline \multicolumn{10}{|l|}{ MHLC } \\
\hline Internality & & & & -.10 & .04 & $6.20 *$ & -.07 & .04 & 2.93 \\
\hline Powerful Others & & & & -.08 & .03 & $6.32 *$ & -.06 & .03 & $4.11^{*}$ \\
\hline Chance & & & & -.06 & .03 & $4.44^{*}$ & -.03 & .03 & 0.97 \\
\hline \multicolumn{10}{|l|}{ Emotion Regulation } \\
\hline Active & & & & & & & -.66 & .33 & $4.05^{*}$ \\
\hline Avoidant & & & & & & & -.44 & .27 & 2.62 \\
\hline
\end{tabular}

Note: MHLC $=$ Multidimensional Health Locus of Control. ${ }^{*} p<.05, * * p<.01$ 